\title{
Endividamento Externo e Controles de Capitais: Uma Análise Computacional de um Modelo Macrodinâmico Pós-keynesiano ${ }^{+}$
}

\author{
- José Luís Oreiro* - INÁcIo Guerberoff LANARI Bó **
}

\begin{abstract}
RESUMO
O presente artigo analisa o impacto dos controles de capitais sobre a trajetória temporal de uma série de variáveis macroeconômicas para economias em desenvolvimento a partir de um modelo pós-keynesiano de economia aberta e sem governo. Inicialmente, apresentamos um modelo macroeconômico que introduz o controle de capitais como variável de escolha de política econômica. A partir da análise de estabilidade do modelo deduzimos um conjunto de valores economicamente plausíveis para os parâmetros. Com base nestes parâmetros analisamos o comportamento dinâmico do grau de utilização da capacidade produtiva, do endividamento externo, das exportações líquidas e da taxa de juros sob diferentes condições iniciais. Na seqüência, analisamos a sensibilidade da economia a choques externos como, por exemplo, variações da taxa de juros internacional e do fluxo internacional de comércio. Nesse contexto, constatamos que os controles de capitais podem contribuir para a redução da volatilidade da dívida externa a choques exógenos, mas amplificam os efeitos desses choques sobre o grau de utilização da capacidade produtiva. Desta forma, a desejabilidade da adoção de controles de capitais é condicional às preferências da sociedade no que se refere à volatilidade do grau de utilização da capacidade vis-à-vis à volatilidade do endividamento externo.
\end{abstract}

\section{Palavras-CHave}

controles de capitais, simulação computacional, dinâmica macroeconômica

\begin{abstract}
This article analyses the effects of capital controls over the time-path of several macroeconomic variables of developing economies by means of a post-Keynesian macroeconomic model for an open economy without government activities. First of all, we present a macroeconomic model that embodies capital controls as an economic policy instrument. After the stability analysis of the model, we deduce a set of economic plausible values for the parameters. Using these parameter values, we describe the dynamical behavior of capacity utilization level, external debt, net exports and interest rate under different initial conditions. Next, we analyze the effects of exogenous shocks - as changes in foreign interest rate or in international trade flow - over our artificial economy. This exercise make us to realize that capital controls can contribute to the reduction of external debt volatility face an exogenous shock, but they enlarge the effects of these shocks over capacity utilization level. So we can state that the desirability of capital controls is conditional to social preferences over volatility of capacity utilization level vis-à-vis volatility of external debt.
\end{abstract}

\section{KEY WORDS}

capital controls, computational simulation, macroeconomic dynamics

\section{JEL CLASSIFICATION}

EI2, E44, F32, F4I

+ Os autores agradecem a ajuda de Breno Lemos (PPGDE/UFPR) na editoração do presente artigo.

* Doutor em Economia (IE/UFRJ), Professor Adjunto do Departamento de Economia da Universidade Federal do Paraná e Pesquisador do CNPq. E-mail : joreiro@ufpr.br.e WebPage: www.joseluisoreiro.ecn.br. Endereço para contato: Departamento de Economia - UFPR Av. Pref. Lothario Meissner 632 - Jd. Botanico - Curitiba - PR. CEP 80210-170.

** Bacharel em Ciência da Computação (IC/UNICAMP). E-mail: inaciog@gmail.com. Web-Page: http://i.nacio.com.br. Endereço para contato: Av. Prof. Luciano Gualberto, trav.3, n.158 Sala C2-50 Cidade Universitária - São Paulo - SP - CEP: 05508-0I0.

(Recebido em março de 2004. Aceito para publicação em dezembro de 2005). 


\section{INTRODUÇÃO}

Atualmente, considerando a instabilidade financeira/cambial típica da experiência mundial recente, mesmo órgãos conservadores, como o FMI, defendem a possibilidade, em certas circunstâncias, do uso temporário de certos tipos de controle de capitais. No próprio mainstream, vários economistas têm criticado os benefícios do processo de liberalização financeira (Tobin, 1978; Rodrik, 1998; Stiglitz, 1999 e 2000) e defendido a introdução de controle de capitais para aumentar a autonomia da política monetária e reduzir a vulnerabilidade externa das economias emergentes.

Embora as razões apresentadas pelos seus defensores possam ser justificativas corretas para a introdução de controles de capitais, uma análise mais profunda sobre o desejo de sua adoção exigiria um esforço para formalizar o debate acerca do controle de capitais selecionando, por meio do qual os efeitos dos controles de capitais sobre variáveis como grau de utilização da capacidade produtiva, endividamento externo, exportações líquidas etc. pudessem ser avaliados. Com efeito, o debate sobre controle de capitais tem sido conduzido ora com base num viés puramente empírico, no qual se avaliam os efeitos de medidas de controles de capitais sobre o desempenho macroeconômico de países selecionados com pouco ou nenhum conteúdo teórico, ora com base num viés teórico generalista, no qual não se avaliam os efeitos secundários e/ou de longo prazo dos referidos controles.

Neste contexto, o presente artigo tem por objetivo avançar no entendimento acerca dos efeitos macroeconômicos da introdução de controles de capitais por economias em desenvolvimento, por meio da construção de um modelo macroeconômico de economia aberta e sem setor governo ${ }^{1}$ de cunho pós-keynesiano. Mais concretamente, o modelo que iremos apresentar será usado para responder a duas questóes fundamentais, a saber:

a) Qual o impacto dos controles de capitais sobre a trajetória temporal de variáveis econômicas selecionadas, como: grau de utilização da capacidade produtiva, endividamento externo como proporção do nível de produto real, taxa de juros doméstica e exportações líquidas como proporção do nível de produto real?

b) Os controles de capitais podem reduzir a fragilidade externa da economia, ou seja, podem reduzir a sensibilidade da mesma a choques externos como, por exem-

1 A ausência do setor governamental não elimina o caráter essencialmente pós-keynesiano de nossa análise, na medida em que, por exemplo, o modelo a ser apresentado aqui trabalha com dinâmica fora do equilíbrio, na linha defendida por Kaldor (1972), e incorpora propensões a poupar diferenciadas, com base na classe de rendimentos na sua estrutura básica, tal como Kaldor (1956) e Pasinetti (1961-62). Além disso, a inclusão da política fiscal em nada alteraria a essência das conclusóes obtidas com o presente modelo, sendo, portanto, um acréscimo desnecessário ao artigo. 
plo, variações da taxa de juros internacional ou variações no fluxo internacional de comércio?

Isto posto, o presente artigo está estruturado em quatro seções incluindo a presente introdução. Na próxima seção iremos apresentar a estrutura básica do modelo teórico utilizado ao longo do artigo. A seção 2 está dedicada aos exercícios de simulação. As conclusões são sumariadas na última seção.

\section{ENDIVIDAMENTO EXTERNO E CONTROLE DE CAPITAIS NUM MODELO TEÓRICO PÓS-KEYNESIANO}

O modelo que será desenvolvido na presente seção ${ }^{2}$ apresenta uma economia na qual (i) o investimento em capital fixo é positivamente influenciado pela razão dívida externa/nível de produto real, devido ao efeito positivo da maior diversidade de fontes de financiamento sobre o risco do tomador; (ii) a mobilidade de capitais no sentido de Mundell (1968) e Fleming (1962) é perfeita, ou seja, vale a assim chamada "paridade descoberta da taxa de juros"; (iii) a taxa de câmbio nominal é fixa e; (iv) o prêmio de risco país é endógeno, variando em conformidade com a dívida externa como proporção do nível de produto real.

Adicionalmente, iremos considerar uma economia que possui controles de capitais na forma de impostos sobre a entrada e/ou saída de aplicaçôes financeiras do país. Esses impostos podem assumir a forma de requerimentos não-remunerados de depósitos no Banco Central por um prazo determinado e/ou impostos sobre a rentabilidade das aplicações financeiras feitas no país. ${ }^{3}$

\subsection{Estrutura do Modelo e o Equilibrio de Curto Prazo}

Consideremos uma economia na qual as empresas operam em mercados oligopolizados, e fixam os seus preços com base num markup fixo sobre os custos diretos de produção, composto por mão-de-obra e insumos importados (cf. Taylor, 1989). Assim, temos:

2 Este modelo é uma extensão do modelo de Oreiro (2004), que é uma formalização das idéias apresentadas em Bresser e Nakano (2003). A utilização deste modelo como base do presente trabalho decorre do fato de que o mesmo estabelece a existência de uma relação entre o nível de endividamento externo e o grau de utilização da capacidade produtiva, relação essa que está ausente da literatura tradicional de macroeconomia aberta, a qual se acha fundamentada no modelo Mundell-Fleming. Essa relação é essencial para que seja possível analisar os efeitos dos controles de capitais sobre o nível de atividade econômica por intermédio dos efeitos desses controles sobre a dinâmica da dívida externa.

3 Uma discussão detalhada sobre os tipos possíveis de controles de capitais pode ser obtida em Paula, Oreiro e Jonas (2003) e também em Carvalho e Sicsú (2004). 


$$
p=(1+\tau)\left[w b+e p_{0}^{*} a_{0}\right]
$$

em que $\tau$ é a taxa de markup, $p$ é o nível de preços doméstico, $w$ é a taxa de salário nominal, $b$ é o requisito unitário de mão-de-obra, $e$ é a taxa nominal de câmbio, $p_{0}{ }^{*}$ é o nível de preços internacional e $a_{0}$ é o requisito unitário de matérias-primas importadas.

Seja $r$ a taxa de lucro e $u$ o grau de utilização da capacidade produtiva. A taxa de lucro pode ser apresentada pela seguinte expressão:

$$
r=\frac{\tau}{1+\tau} u
$$

O mercado de bens está em equilíbrio quando a condição abaixo é atendida:

$$
p C+p I+p E=p X
$$

em que $p C$ é o valor nominal dos gastos de consumo, $p I$ é o valor nominal dos gastos de investimento, $p E$ é o valor nominal das exportações líquidas e $p X$ é o valor nominal do nível de produção.

Iremos supor a existência de duas classes sociais - capitalistas e trabalhadores -, as quais se diferenciam entre si com base na origem dos seus rendimentos - lucros e salários - e com base na propensão a consumir da renda disponível. Nesse contexto, iremos supor que os trabalhadores "consomem tudo o que ganham", de forma que a sua propensão a consumir é igual a um. ${ }^{4}$ Por outro lado, os capitalistas consomem uma fração $c_{s}$ dos seus rendimentos (os quais são constituídos unicamente de lucros), poupando uma fração $s_{c}=\left(1-c_{c}\right)$ da sua renda. Sendo assim, o valor nominal dos gastos de consumo é dado por:

$$
p C=w b X+\left(1-s_{c}\right) r p K
$$

em que $p K$ representa o valor nominal do estoque de capital.

Substituindo (4) em (3) temos, após as manipulações necessárias, que:

$$
\frac{I}{X}+\frac{E}{X}-s_{c} \frac{\tau}{1+\tau}-q a_{0}=0
$$

4 Ou seja, a sua propensão a poupar é igual a zero. 
em que $q=\frac{e p_{0}^{*}}{p}$, ou seja, definido como a taxa de câmbio real.

O investimento é composto por três determinantes: uma fração autônoma $\left(\alpha_{0}\right)$, uma que depende da diferença entre a taxa de lucro e taxa de juros $\left(\alpha_{1}[r-i]\right)$ e por fim um componente que depende do endividamento externo como proporção do nível de produto real $\left(\alpha_{2} z^{\psi}\right)$. Iremos supor que um aumento do endividamento externo como proporção do nível de produto real irá resultar num aumento menos do que proporcional do investimento, ou seja, $\psi<1 .^{5}$ Desta forma:

$$
\frac{I}{X}=\alpha_{0}+\alpha_{1}[r-i]+\alpha_{2} z^{\psi} \quad 0<\psi<1 ; \alpha_{0}>0 ; \alpha_{1}>0 ; \alpha_{2}>0
$$

Já as exportações líquidas dependem de um componente autônomo $\left(\varepsilon_{0}\right)^{6}$ e negativo do nível de utilização da capacidade produtiva, pois é feita a suposição usual de que com o aumento da atividade econômica há um aumento do nível global de importações. Temos assim que:

$$
\frac{E}{X}=\varepsilon_{0}-\varepsilon_{1} u \quad \varepsilon_{0}>0 ; \varepsilon_{1}>0
$$

Num contexto em que a mobilidade de capitais não é perfeita devido à existência de controles de capitais, a taxa de juros doméstica pode se distanciar do patamar determinado pela paridade descoberta da taxa de juros. Uma das razóes para a introdução de controles de capitais é precisamente dar mais autonomia à condução da política monetária. Mais precisamente, os controles de capitais permitem que as autoridades monetárias tenham um maior grau de liberdade para fixar a taxa de juros básica da economia em um patamar condizente com o atendimento dos objetivos domésticos (inflação e desemprego). Esse comportamento é resultado da redução do papel da arbitragem na determinação da taxa de juros, já que há um desestímulo financeiro à entrada e saída indiscriminada de capital financeiro na economia analisada.

5 Conforme aponta Oreiro (2004), é perfeitamente plausível supor a inclusão da variável endividamento externo como proporção do produto real na função investimento. A sua incorporação nesta função reproduz as restrições de financiamento externo à decisão de investimento em capital fixo, uma vez que o investimento, em uma economia aberta, pode ser limitado pela capacidade de importar bens de capital, isto é, pela restrição de divisas (cf. Bresser e Nakano, 2003). A suposição $\psi<1$ advém da idéia de que nem todo o endividamento externo é destinado ao financiamento da compra de capital fixo, ou seja, nem todo endividamento externo é tomado para investimento.

6 Como estamos considerando uma economia que opera sob um regime de câmbio fixo e na qual os salários nominais, as margens de lucro e - por conseguinte - os preços domésticos são fixos, segue-se que a taxa real de câmbio $q$ pode ser tomada como uma constante e, como tal, incluída como um dos determinantes da parcela autônoma das exportações líquidas na equação (7). 
Dessa forma, iremos supor que a taxa de juros doméstica é formada por uma média entre a "taxa de juros desejada" pelo Banco Central, ou seja, o nível da taxa de juros doméstica que é compatível com o atendimento dos objetivos da política econômica doméstica, e o valor é dado pela "paridade descoberta da taxa de juros". Esta ponderação - definida pela variável $k$ - reflete o nível dos controles de capitais. Quanto maior o controle, maior o peso da taxa de juros desejada pelo Banco Central na determinação do valor efetivo da taxa de juros doméstica.

Seja $\bar{i}$ a taxa desejada de juros pelo Banco Central e seja $i^{*}+\rho$ (onde $i^{*}$ é a taxa de juros internacional e $\rho$ é o prêmio de risco-país) o valor da taxa de juros doméstica compatível com a "paridade descoberta da taxa de juros" na ausência de controles de capitais e supondo um regime de câmbio fixo. A taxa de juros doméstica pode ser escrita da seguinte forma:

$$
i=(1-k)\left(i^{*}+\rho\right)+k \bar{i} \quad ; \quad 0<k<1
$$

No que se refere ao prêmio de risco-país, iremos supor que o mesmo possui um patamar mínimo $\rho_{0}$, igual ao prêmio de risco exigido dos países com "investment grade". Esse nível mínimo de risco é obtido quando a dívida externa como proporção do nível de produto real é igual a zero. Para valores positivos da dívida externa como proporção do nível de produto real, o prêmio de risco é suposto uma função crescente do nível do endividamento externo. Em outras palavras, o prêmio de risco é endógeno. Sendo assim, temos que:

$$
\rho=\rho_{0}+\rho_{1} z \quad \rho_{0}>0 ; \rho_{1}>0
$$

Substituindo (9) em (8), obtemos a seguinte expressão:

$$
i=(1-k)\left(i^{*}+\rho_{0}+\rho_{1} z\right)+k \bar{i}
$$

Substituindo (10) em (6), obtemos uma equação que determina o investimento como proporção do PIB real como função do endividamento externo e da lucratividade:

$$
\frac{I}{X}=\alpha_{0}+\alpha_{1}\left[r-(1-k)\left(i^{*}+\rho_{0}+\rho_{1} z\right)-k \bar{i}\right]+\alpha_{2} z^{\psi}
$$

Colocando $u$ em evidência na equação (2) e substituindo a resultante em (7), obtemos:

$$
\frac{E}{X}=\varepsilon_{0}-\varepsilon_{1} \frac{(1+\tau)}{\tau} r
$$


Substituindo (6a) e (7a) em (5), e colocando $r$ em evidência obtemos a seguinte expressão:

$r=\frac{1}{\left(\varepsilon_{1} m^{-1}-\alpha_{1}\right)}\left[\left(\alpha_{2} z^{\psi}-\alpha_{1}(1-k) \rho_{1} z\right)+\Theta-\alpha_{1}\left[k \bar{i}+(1-k)\left(i^{*}+\rho_{0}\right)\right]\right]$

em que $m=\frac{\tau}{1+\tau}$ é a participação dos lucros na renda e $\Theta \equiv \alpha_{0}+\varepsilon_{0}-s_{c} m-q a_{0}$.

A equação (11) apresenta o valor da taxa corrente de lucro para o qual o mercado de bens se encontra em equilíbrio, ou seja, para o qual a demanda agregada é igual à oferta. Trata-se do valor de equilíbrio de curto prazo da taxa de lucro.

O equilíbrio de curto prazo será estável se a condição $\varepsilon_{1} m^{-1}-\alpha_{1}>0$ for atendida. ${ }^{7}$

Diferenciando (11) com respeito a $r$ e $z$, obtemos a seguinte expressão:

$$
\frac{\partial r}{\partial z}=\frac{1}{\left(\varepsilon_{1} m^{-1}-\alpha_{1}\right)}\left[\psi \alpha_{2} z^{\psi-1}-\alpha_{1}(1-k) \rho_{1}\right]
$$

O sinal de $\frac{\partial r}{\partial z}$ dependerá de $\psi \alpha_{2} z^{\psi-1}-\alpha_{1}(1-k) \rho_{1}$, que varia com $z$. Dessa forma, à medida que $z$ aumenta, $\frac{\partial r}{\partial z}$ passará de positivo para negativo, caracterizando uma relação não-linear entre a lucratividade e o endividamento com o formato apresentado pela Figura 1 abaixo:

FIGURA I - LUCR ATIVIDADE EM FUNÇÃO DO ENDIVIDAMENTO

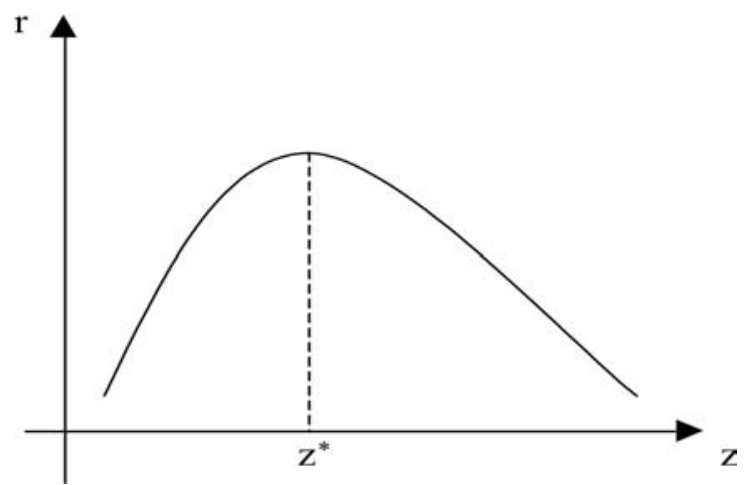

7 Esta condição diz que a sensibilidade das exportações líquidas como proporção do nível de produto real a variaçóes no grau de utilização da capacidade produtiva (participação dos lucros na renda) deve ser maior do que a sensibilidade do investimento como proporção do produto real ao diferencial de taxa de lucro e taxa de juros doméstica. 
De (12) sabemos que $\frac{\partial r}{\partial z}>0$ se a seguinte condição for atendida:

$$
z<\left(\frac{\psi \alpha_{2}}{\alpha_{1}(1-k) \rho_{1}}\right)^{\frac{1}{1-\psi}}=z^{*}
$$

Por intermédio da equação (13) observa-se que o sinal de $\frac{\partial r}{\partial z}$ será positivo quando $z<z^{*}$, e negativo quando $z>z^{*}$. Desta forma, a relação entre a taxa de lucro ou o grau de utilização da capacidade produtiva e o endividamento externo como proporção do nível de produto real será não-linear. É importante notar que a Figura 1 não será exatamente uma parábola, como podemos perceber por meio da equação (11). O desenho geométrico de uma parábola só seria possível caso a equação (11) fosse quadrática em $z$. Ainda assim, admitindo que z não pode ser negativo, ao passo que economias em desenvolvimento são necessariamente devedoras líquidas, podemos encarar a Figura 1 como uma representação qualitativa de uma curva que é ascendente em $z$ $<z^{*}$, e descente em $z>z^{*}$.

\subsection{Dinâmica de Longo Prazo e Equilíbrios Múltiplos}

Para analisar a dinâmica de longo prazo dessa economia iremos inicialmente supor que o mercado de bens se ajusta lentamente às divergências entre demanda e oferta agregadas. Dessa forma, a dinâmica da taxa de lucro é explicada pela seguinte equação diferencial:

$$
\dot{r}=\gamma(E D B)
$$

Em que:

$E D B=\left(\alpha_{1}-\varepsilon_{1} m^{-1}\right) r+\left(\alpha_{2} z^{\psi}-\alpha_{1}(1-k) \rho_{1} z\right)+\Theta-\alpha_{1}\left(k \bar{i}+(1-k)\left(i^{*}+\rho_{0}\right)\right)$ é o excesso de demanda no mercado de bens. ${ }^{8}$

Seguindo Simonsen e Cysne (1995), a equação diferencial que descreve a dinâmica temporal da dívida externa é dada por:

8 A equação (14) mede o excesso de demanda por bens porque sua origem é a identidade macroeconômica, que capta o nível de demanda agregada que se ajusta com a alocação da renda a uma velocidade $\gamma$ ao longo do tempo. Neste sentido, a equação (11) significa apenas uma maneira particular de escrever a identidade macroeconômica em seu equilíbrio de curto prazo. 


$$
\dot{D}=i^{e} D-H
$$

em que $D$ é o estoque total de endividamento externo, $H$ é a transferência líquida de recursos para o exterior e $i^{e}$ é a taxa de juros da dívida externa. A equação (15) revela, portanto, a variação do endividamento externo ao longo do tempo.

Diferentemente da taxa de juros doméstica, a taxa de juros da dívida externa não é alterada pelo controle de capitais, ${ }^{9}$ sendo determinada, portanto, pela equação:

$$
i^{e}=i^{*}+\rho
$$

Diferenciando $z^{10}$ com respeito ao tempo, obtemos a seguinte expressão:

$$
\dot{z}=\frac{\dot{D}}{X}-\frac{\dot{X}}{X} \frac{D}{X}
$$

Substituindo (15) em (17) e supondo que a taxa de crescimento do produto real é exógena e igual a $g,{ }^{11}$ obtemos a seguinte expressão:

$$
\dot{z}=\left(i^{e}-g\right) z-\frac{H}{X}
$$

A transferência líquida de recursos para o exterior nada mais é, na economia em consideração, do que o valor das exportações líquidas. ${ }^{12}$ Sendo assim, a expressão final para a dinâmica da dívida externa como proporção do nível de produto real é dada por:

$$
\dot{z}=\left(i^{*}+\rho_{0}+\rho_{1} z-g\right) z-\varepsilon_{0}+\varepsilon_{1} m^{-1} r
$$

9 Via de regra, para economias em desenvolvimento ou emergentes, a dívida externa é denominada em moeda forte e é pré-fixada ou possui como referencial um índice que não seja referente à estrutura macroeconômica do país tomador. 10 Lembre-se que $z=\frac{D}{X}$, pois se trata do nível de endividamento externo como proporção do nível de
produto real.

11 Essa suposição é necessária, uma vez que o modelo aqui apresentado não possui nenhuma equação capaz de determinar a taxa de crescimento do produto. A suposição usual dos modelos pós-keynesiano de crescimento e distribuição de renda é que, em função da hipótese de coeficientes fixos, a taxa de crescimento do estoque de capital é igual à taxa de crescimento do produto. Contudo, como a utilização da capacidade produtiva é uma variável endógena neste modelo - e em outros modelos pós-keynesiano - segue-se que essa igualdade só é válida em steady-state, uma vez que nessa posição de repouso o grau de utilização da capacidade produtiva é constante. Fora do steady-state, o grau de utilização da capacidade produtiva pode variar ao longo do tempo, de forma que a taxa de crescimento do produto poderá ser maior ou menor do que a taxa de crescimento do estoque de capital.

12 Estamos supondo que o saldo da balança de serviços não-fatores é igual a zero. 
Em steady-state, a taxa de lucro e o endividamento externo são constantes ao longo do tempo. Isto permite definir o lócus $\dot{r}=0$ e o lócus $\dot{z}=0$, cujas inclinações são dadas respectivamente pelas seguintes equações:

$$
\begin{aligned}
& \left(\frac{\partial r}{\partial z}\right)_{\mid \dot{r}=0}=-\frac{\left[\psi \alpha_{2} z^{\psi-1}-\alpha_{1}(1-k) \rho_{1}\right]}{\left(\alpha_{1}-\varepsilon_{1} m^{-1}\right)} \\
& \left(\frac{\partial r}{\partial z}\right)_{\mid i=0}=-\frac{\left(i^{*}+\rho_{0}\right)-g+2 \rho_{1} z}{\varepsilon_{1} m^{-1}}
\end{aligned}
$$

Anteriormente foi demonstrado que o lócus que descreve as combinaçóes de $r$ e $z$ para as quais o mercado de bens se encontra em equilíbrio tem o formato de uma parábola com concavidade voltada para baixo. Na equação (21) podemos constatar que - supondo $i^{*}+\rho_{0}+2 \rho_{1} z>g$, condição para a qual $i^{e}>g$ é suficiente - o lócus que descreve as combinações de $r$ e $z$, para as quais a dívida externa é constante ao longo do tempo, tem inclinação negativa para todos os valores de $z$.

Nesse contexto, uma das configuraçóes possíveis de equilíbrio de longo prazo da economia em consideração corresponderia a visualizada por intermédio da Figura 2 abaixo.

\section{FIGURA 2 - EQUILÍBRIOS DE LONGO PRAZO}

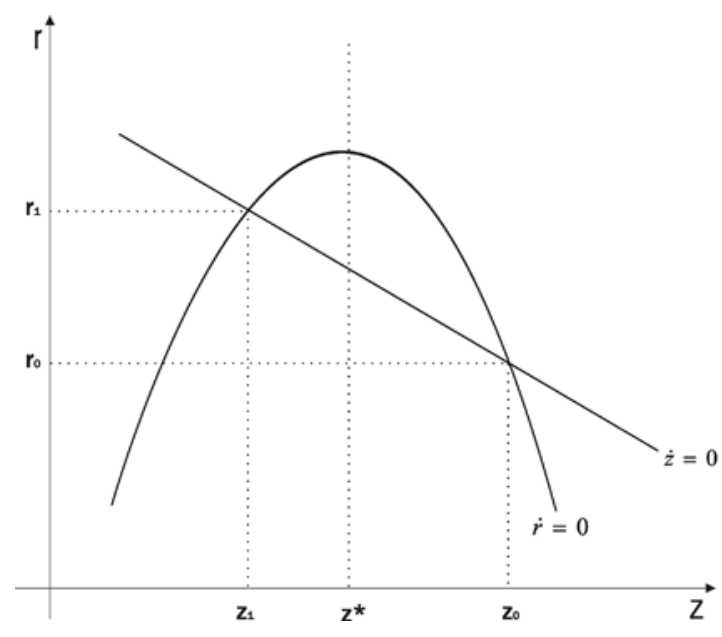

Na Figura 2 visualizamos a existência de duas posiçóes de equilíbrio de longo prazo. A primeira caracterizada por uma lucratividade elevada $\left(\mathbf{r}_{1}\right)$ e um baixo nível de endi- 
vidamento externo $\left(\mathbf{z}_{1}\right)$ - que chamaremos de equilíbrio com baixo endividamento - e a segunda caracterizada por uma lucratividade baixa $\left(\mathbf{r}_{0}\right)$ e um alto nível de endividamento externo $\left(\mathbf{z}_{0}\right)$.

\subsection{Análise de Estabilidade no Caso em que $0<\gamma<\infty$}

Utilizaremos a metodologia traço-determinante para analisar a estabilidade do sistema.

A matriz Jacobiana do sistema é dada por:

$$
J=\left(\begin{array}{ll}
\frac{\partial \dot{r}}{\partial r} & \frac{\partial \dot{r}}{\partial z} \\
\frac{\partial \dot{z}}{\partial r} & \frac{\partial \dot{z}}{\partial z}
\end{array}\right)=\left(\begin{array}{cc}
\gamma\left(\alpha_{1}-\varepsilon_{1} m^{-1}\right) & \gamma\left(\psi \alpha_{2} z^{\psi-1}-\alpha_{1}(1-k) \rho_{1}\right) \\
\varepsilon_{1} m^{-1} & \left(i^{*}+\rho_{0}-g\right)+2 \rho_{1} z
\end{array}\right)
$$

Em que:

$$
\begin{aligned}
& \gamma\left(\alpha_{1}-\varepsilon_{1} m^{-1}\right)<0 \\
& \gamma\left(\psi \alpha_{2} z^{\psi-1}-\alpha_{1}(1-k) \rho_{1}\right) \\
& \left(i^{*}+\rho_{0}-g\right)+2 \rho_{1} z>0 \\
& \varepsilon_{1} m^{-1}>0
\end{aligned}
$$

Os valores do determinante e do traço do determinante são:

$$
\begin{aligned}
& \operatorname{DET}(J)=(22) *(24)-(23) *(25) \\
& \operatorname{TR}(J)=(22)+(24)
\end{aligned}
$$

O sistema será instável do tipo trajetória de sela se o determinante da matriz Jacobiana for negativo (cf. Takayama, 1993).

Se (23) for maior que zero, o determinante será negativo. Dividindo (23) por gama e isolando $z$, temos: 


$$
z<\left(\frac{\psi \alpha_{2}}{\alpha_{1}(1-k) \rho_{1}}\right)^{\frac{1}{1-\psi}}=z^{*}
$$

De (26) observamos que o equilíbrio com baixo endividamento, que se situa à esquerda de $z^{*}$, é necessariamente instável do tipo trajetória de sela.

Como o equilíbrio com alto endividamento encontra-se à direita de $z^{*}$, segue-se que o mesmo pode ser estável, dependendo ainda do traço da matriz Jacobiana. Para que esse equilíbrio seja estável é necessário que o traço seja negativo. Temos, então, que:

$$
\gamma\left(\alpha_{1}-\varepsilon_{1} m^{-1}\right)>\left(i^{*}+\rho_{0}-g\right)+2 \rho_{1} z
$$

Isso ocorrerá se:

$$
z<\frac{\gamma\left(\alpha_{1}-\varepsilon_{1} m^{-1}\right)-\left(i^{*}+\rho_{0}-g\right)}{2 \rho_{1}}=z^{* *}
$$

A condição (27) é condição necessária, mas ainda não suficiente, para a estabilidade. Além disso, é necessário que o determinante seja positivo, ou seja, que $z>z^{*}$. Em outras palavras, o equilíbrio com alto endividamento será estável se $z^{*}<z^{* *}$. Para que isso ocorra a seguinte condição deve ser atendida:

$$
\left(\frac{\psi \alpha_{2}}{\alpha_{1}(1-k) \rho_{1}}\right)^{\frac{1}{1-\psi}}<\frac{\gamma\left(\alpha_{1}-\varepsilon_{1} m^{-1}\right)-\left(i^{*}+\rho_{0}-g\right)}{2 \rho_{1}}
$$

Colocando $g$ em evidência, temos:

$$
g>2 \rho_{1}(1-k)^{\frac{1}{\psi-1}}\left(\frac{\psi \alpha_{2}}{\alpha_{1} \rho_{1}}\right)^{\frac{1}{1-\psi}}-\gamma\left(\alpha_{1}-\varepsilon_{1} m^{-1}\right)+i^{*}+\rho_{0}=g^{*}
$$

13 A manipulação algébrica estabelecida em (23) foi feita com vistas a permitir uma comparação entre o z ótimo para o mercado de bens e para a evolução do endividamento e assim entendermos a estabilidade dos pontos de equilíbrio. 
Para que o equilíbrio com alto endividamento seja estável é necessário que a taxa de crescimento do produto real seja maior do que um certo nível $g^{*}$, o qual depende, entre outras variáveis, do nível dos controles de capitais. Desta maneira, quanto maior o controle de capitais, isto é, quanto maior o valor de $k$, maior será o valor de $g^{*}$. Assim, um intenso controle de capitais pode comprometer o equilíbrio do sistema, fazendo com que o equilíbrio com alto endividamento também será instável.

\subsection{Análise de Estabilidade no Caso em que $\gamma \rightarrow \infty$}

Iremos agora relaxar a hipótese de que o mercado de bens se ajusta lentamente a uma situação de excesso de demanda, ou seja, iremos supor que, do ponto de vista da análise de longo prazo, na qual o endividamento externo como proporção do nível de produto real é uma variável endógena, o grau de utilização da capacidade produtiva corresponde ao seu valor de equilíbrio. Desta forma, o sistema dinâmico apresentado anteriormente será reduzido a uma única equação diferencial - a expressão (19) - em que a dinâmica do endividamento externo depende apenas do valor assumido pela variável $z$, dado que a taxa de lucro terá assumido o seu valor de equilíbrio, sendo uma função não linear de $z$, de acordo com a equação (12).

Nesse contexto, a análise da estabilidade do sistema fica bastante simplificada. Isto porque a economia estará operando continuamente sobre o lócus $\dot{r}=0$ e a sua dinâmica se dará apenas pela equação (19). Se a economia estiver operando num ponto sobre o lócus $\dot{r}=0$ acima do lócus $\dot{z}=0$, então a combinação lucratividade-endividamento externo será tal que a dívida externa como proporção do nível de produto real irá aumentar ao longo do tempo (Figura 3). Contudo, se a economia estiver operando num ponto sobre o lócus $\dot{r}=0$ abaixo do lócus $\dot{z}=0$, então a combinação lucratividade-endividamento externo será tal que a dívida externa como proporção do nível de produto real irá diminuir ao longo do tempo. Sendo assim, o equilíbrio com alto endividamento será estável, ao passo que o equilíbrio com baixo endividamento será instável. Isso significa que se o nível inicial de endividamento externo for superior ao nível correspondente ao equilíbrio com baixo endividamento, a economia irá convergir para uma posição de equilíbrio de longo prazo caracterizada por um alto endividamento externo. 


\section{FIGURA 3 - DINÂMICA DE LONGO PRAZO COM AJUSTE INSTANTÂNEO NO MERCADO DE BENS}

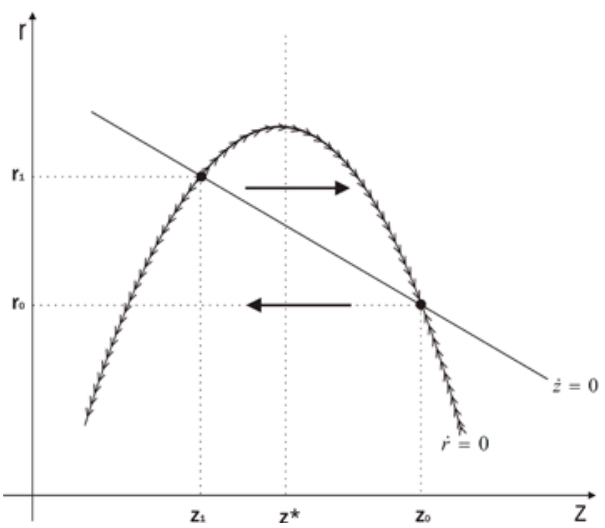

\section{SIMULAÇÃO COMPUTACIONAL DO MODELO TEÓRICO}

Nesta seção iremos utilizar as equações diferenciais do modelo teórico desenvolvido na seção anterior para simular em computador as possíveis trajetórias no tempo de uma série de variáveis econômicas relevantes, a saber: a lucratividade, a dívida externa como proporção do nível de produto real, a taxa de juros doméstica e as exportações líquidas como proporção do nível de produto real.

Na seção anterior foi especificada a estrutura do modelo teórico a partir do qual a simulação computacional será conduzida, e foram analisadas as condições de existência e estabilidade das posições de equilíbrio de longo prazo. Agora iremos complementar a análise qualitativa feita na seção 1 por intermédio de simulação em computador. $\mathrm{O}$ objetivo da simulação é deduzir um conjunto de valores economicamente plausíveis para os parâmetros das equações estruturais do modelo. Esses valores serão usados para:

(i) comparar a trajetória temporal de uma série de variáveis econômicas sob diferentes regimes de conversibilidade da conta de capitais, a saber: conversibilidade plena e conversibilidade parcial da conta de capitais;

(ii) analisar a sensibilidade da economia a choques externos sob diferentes regimes de conversibilidade da conta de capitais.

\subsection{A Metodologia de Simulação}

A simulação de um modelo econômico possibilita analisar algumas propriedades práticas do modelo, assim como verificar as grandezas numéricas envolvidas nas dinâmicas estudadas na análise qualitativa. 
Existem duas formas de se realizar uma simulação econômica. Na primeira, utilizando uma metodologia que chamaremos de estratégia bottom-up, constrói-se um modelo computacional com vistas à simulação. As funções comportamentais e alguns parâmetros são definidos e desenhados na modelagem com o objetivo específico de simulação computacional. Em geral ganhamos em precisão temporal e em flexibilidade dos comportamentos, mas perdemos em poder de análise. A estratégia bottom-up é utilizada quando queremos nos aproveitar da flexibilidade da linguagem computacional comparativamente à algébrica, como comportamentos condicionais, repetiçôes diferenciadas em funções diversas, entre outros comportamentos que não poderiam ser reproduzidos por meio da abordagem tradicional (ou seria de utilização desnecessariamente complexa).

A segunda forma utiliza uma metodologia que chamaremos de estratégia top-down. O objetivo é adaptar um modelo econômico já existente a uma simulação. Sem alterar as equações do modelo, testa-se o comportamento do mesmo sob parâmetros reais ou plausíveis, e se verifica o comportamento no tempo das variáveis econômicas. Como se trata de uma análise numérica de um trabalho qualitativo, muitas vezes pode-se chegar a conclusão que certas condições tidas como teoricamente possíveis na análise qualitativa se mostram implausíveis ou irrealistas na simulação computacional. Dessa forma, a estratégia top-down é um importante complemento à análise qualitativa, pois nos permite ter uma idéia mais clara da relevância das condições teóricas nas quais certos comportamentos podem ou não ser observados. Outro resultado da análise quantitativa proporcionada por esse método é a análise da plausibilidade das oscilaçôes observadas nos modelos qualitativos, como ciclos e oscilações convergentes.

A metodologia utilizada neste trabalho é a segunda. Partindo de um modelo teórico matemático elaborado da forma tradicional, atribuímos números plausíveis aos parâmetros das funções comportamentais do modelo. ${ }^{14}$ Alguns desses parâmetros, no entanto, são de magnitude desconhecida. Para esses parâmetros, utilizamos a metodologia do princípio da correspondência de Samuelson, ou seja, atribuímos os valores necessários aos mesmos para que a sua dinâmica temporal seja minimamente realista ou plausível. ${ }^{15}$

Por exemplo, atribuindo valores para os parâmetros "observáveis" do modelo com base naquilo que parece ser plausível para uma economia como a brasileira, e ajustando os valores dos parâmetros para os quais nenhuma estimativa a priori pode ser feita com base nas condições de existência dos equilíbrios com baixo e alto endividamento, verificamos que a estabilidade do equilíbrio com alto endividamento no caso em que

14 Essa atribuição é feita com base nas estimativas a respeito dos valores dos mesmos.

15 Nas palavras de Samuelson: "Constitui a tarefa central (...) demonstrar como o problema da estabilidade do equilibrio está intimamente associado ao problema da obtenção de teoremas fecundos de estática comparada. Essa dualidade constitui o que chamei de princípio da correspondência.” (1945, p. 220). 
$\gamma<\infty$ só seria possível para valores implausíveis dos parâmetros do modelo. Com efeito, o atendimento da condição (28) exige que a taxa de crescimento do nível de produto real seja significativamente maior que $6 \%$. Mais ainda, se adicionarmos a condição necessária de o ponto de equilíbrio com alto endividamento estar situado na região entre $z^{*}$ e $z^{* *}$, é necessária uma taxa de crescimento de $24 \%$ ao ano. Dessa forma, nos deparamos com um modelo sem equilíbrio estável para valores plausíveis dos parâmetros.

A metodologia acima definida abre campo para duas questôes fundamentais. A primeira refere-se ao momento no qual o pesquisador deve encerrar a sua busca por um conjunto plausível de parâmetros. A segunda questão está relacionada à seleção dos fatos estilizados da dinâmica capitalista, os quais são utilizados como padrão de comparação para as trajetórias dinâmicas geradas pelo modelo teórico.

No que se refere à primeira questão, deve-se observar que não há nenhum critério objetivo com base no qual se possa determinar qual é o momento em que o pesquisador deve encerrar a sua busca por um conjunto plausível de parâmetros. Neste contexto, o pesquisador não tem outra opção a não ser utilizar a racionalidade limitada de Simon (1980) e se contentar com um "bom" conjunto de parâmetros, ainda que possam existir parâmetros melhores, isto é, um conjunto de parâmetros que seja capaz de gerar trajetórias dinâmicas mais aderentes àquelas que se observam no mundo real.

Uma crítica comum ao procedimento exposto acima é que a grande complexidade dos modelos de simulação em conjunto com a existência de parâmetros livres, ou seja, parâmetros cujos valores numéricos precisos não têm embasamento empírico, proporcionam ao construtor do modelo graus de liberdade quase infinitos na obtenção dos resultados desejados. Em outras palavras, o pesquisador poderia obter virtualmente qualquer resultado a partir de seu modelo teórico desde que disponha do tempo e da paciência necessária para testar diversos conjuntos de valores dos parâmetros até obter um conjunto de valores que lhe proporcione o resultado desejado.

Essa crítica é apenas parcialmente correta. Com efeito, tal como foi dito na exposição da metodologia de simulação apresentada anteriormente, a obtenção de um "bom" conjunto de parâmetros envolve um processo de tentativa e erro no qual os resultados obtidos a partir de uma determinada especificação numérica do modelo são contrastados com uma série de fatos estilizados. Contudo, os graus de liberdade do pesquisador podem ser substancialmente reduzidos se o número de fatos estilizados a serem explicados for suficientemente grande. Nesse contexto, um "modelo ruim", isto é, um modelo que abstrai algum aspecto essencial da realidade econômica, não será capaz de explicar uma boa quantidade desses fatos estilizados, qualquer que seja o conjunto de valores escolhidos para os parâmetros e para as condiçôes iniciais. Dessa forma, a 
seleção de um número razoavelmente grande de fatos estilizados sobre a dinâmica das economias capitalistas torna-se um elemento essencial, não só para a realização de um bom processo de calibragem dos parâmetros do modelo, como também um critério de julgamento da relevância e da plausibilidade do modelo que está sendo apresentado.

Os economistas, via de regra, têm um grande desconforto com posições de equilíbrio que não sejam estáveis. Esse desconforto é baseado em duas posições. A primeira, defendida por Samuelson (1945), estabelece que um equilíbrio instável é uma posição transitória e, como tal, não-observável empiricamente. ${ }^{16}$ A segunda, defendida por Blatt (1983), estabelece que a instabilidade do equilíbrio gera uma dinâmica tal para as variáveis endógenas que o sistema econômico converge para um estado impossível ou economicamente inviável num intervalo finito (embora, em alguns casos, longo) de tempo.

Esse raciocínio, contudo, não nos parece suficientemente convincente para justificar o abandono de um modelo teórico no qual as posições de equilíbrio não são estáveis. Consideremos, por exemplo, a literatura teórica que trata do tema da hiperinflação. Essa literatura baseia-se em modelos de agente representativo com horizonte infinito de planejamento, nos quais a moeda é o único ativo, ou seja, a única forma pela qual o agente representativo pode carregar poder de compra ao longo do tempo (cf. Blanchard e Fisher, 1989, p. 239-245).

Essa classe de modelos admite a existência de uma posição de equilíbrio estacionário no qual o valor real dos saldos monetários é constante ao longo do tempo. Esse equilíbrio é, contudo, instável: se o valor real dos saldos monetários for menor do que o de equilíbrio, então a economia entrará numa dinâmica tal que esse valor irá convergir para zero num intervalo finito de tempo. Ou seja, o valor da moeda irá tender a zero no longo prazo. Esta posição é claramente inviável do ponto de vista econômico, uma vez que sua concretização significaria a reversão da tecnologia de trocas para um sistema de escambo, o que não é compatível com o alto grau de especialização e divisão do trabalho existente numa economia capitalista. No entanto, essa instabilidade não é vista como uma anomalia ou algo que deponha contra a utilidade dessa classe de modelos. Isto porque a hiperinflação, embora seja um evento raro, não é um fenômeno impossível de ocorrer. De fato, no século XX podemos listar pelo menos meia dúzia de experiências históricas de hiperinflação.

Com base nessa analogia, podemos afirmar que a utilidade analítica de um modelo que apresente equilíbrios instáveis consiste precisamente em mostrar a necessidade da

16 Essa posição de Samuelson nos parece irrelevante. É verdade que um equilíbrio instável é, por definição, transitório, pois qualquer afastamento com respeito a essa posição irá detonar mecanismos que irão amplificar esse desvio. Daqui não se segue, no entanto, que a dinâmica fora do equilíbrio seja um evento efêmero ou transitório. De fato, a instabilidade do equilíbrio fará com que a economia opere permanentemente em desequilíbrio. Neste contexto, a dinâmica fora do equilíbrio passa a ser o objeto central da investigação científica. 
realização de reformas estruturais, lideradas ou não pelo governo, com o objetivo de estabilizar o sistema econômico, evitando assim a emergência de estados economicamente inviáveis no longo prazo.

Nas simulações realizadas a seguir iremos analisar o comportamento das variáveis endógenas num intervalo de tempo curto o suficiente para evitar que estas assumam valores impossíveis ou implausíveis. O objetivo é realizar o que iremos denominar de dinâmica comparativa, ou seja, iremos comparar as trajetórias temporais das variáveis endógenas que podem ser obtidas a partir de diferentes valores dos parâmetros do modelo. Um interesse particular será devotado à dinâmica comparada dos controles de capitais. Em outras palavras, iremos comparar as trajetórias das diversas variáveis endógenas que podem ser obtidas a partir de diferentes valores para o nível dos controles de capitais.

\subsection{O Processo de Escolha dos Valores dos Parâmetros}

Tomando como base o princípio de que os valores dos parâmetros devem ser valores numéricos que sejam plausíveis do ponto de vista econômico, e considerando que a economia em análise diz respeito a um país emergente, que possui uma grande (mas não perfeita) mobilidade de capitais e um alto endividamento externo, consideramos o seguinte conjunto de parâmetros nos exercícios de simulação:

TABELA 1 - PARÂMETROS DE SIMULAÇÃO

\begin{tabular}{|c|c|c|c|c|c|}
\hline Parâmetro & Descrição & Valor & Parâmetro & Descrição & Valor \\
\hline$S_{c}$ & Propensão a poupar dos capitalistas & 0.15 & $\varepsilon_{0}$ & $\begin{array}{l}\text { Determinante autônomo das } \\
\text { exportações líquidas }\end{array}$ & 0.1 \\
\hline$m$ & Participação dos lucros na renda & 0.5 & $\varepsilon_{1}$ & $\begin{array}{l}\text { Sensibilidade das importações } \\
\text { ao nível de atividade }\end{array}$ & 0.33 \\
\hline$i^{*}$ & Taxa de juros internacional & 0.02 & $\psi$ & $\begin{array}{l}\text { Fator de decrescimento do in- } \\
\text { vestimento com endividamento }\end{array}$ & 0.2 \\
\hline$\rho_{0}$ & $\begin{array}{l}\text { Prêmio de risco de países com } \\
\text { investment grade }\end{array}$ & 0.03 & $\bar{i}$ & $\begin{array}{l}\text { Meta de taxa de juros da política } \\
\text { monetária autônoma }\end{array}$ & 0.03 \\
\hline$\rho_{1}$ & $\begin{array}{l}\text { Sensibilidade do prêmio de risco ao } \\
\text { estoque da dívida }\end{array}$ & 0.2 & $a_{0}$ & $\begin{array}{l}\text { Requisito unitário de matérias- } \\
\text { primas importadas }\end{array}$ & 0.5 \\
\hline$\alpha_{0}$ & $\begin{array}{l}\text { Determinante autônomo do inves- } \\
\text { timento }\end{array}$ & 0.067 & $q$ & Taxa real de câmbio & 0.2 \\
\hline$\alpha_{1}$ & $\begin{array}{l}\text { Sensibilidade do investimento ao } \\
\text { diferencial juros/lucratividade }\end{array}$ & 0.6 & $g$ & Taxa de crescimento do PIB & 0.035 \\
\hline$\alpha_{2}$ & $\begin{array}{l}\text { Sensibilidade do investimento ao } \\
\text { estoque da dívida }\end{array}$ & 0.1 & $\gamma$ & $\begin{array}{l}\text { Velocidade de ajuste no mer- } \\
\text { cado de bens }\end{array}$ & 0.1 \\
\hline
\end{tabular}


Na Tabela 1 os valores dos parâmetros $\alpha_{1}, \alpha_{2}, \rho_{1}, \varepsilon_{1}, \psi$ e $\gamma$ foram escolhidos de forma a permitir a existência de duas posições de equilíbrio de longo prazo, tal como no modelo teórico desenvolvido na seção anterior. Os demais parâmetros foram escolhidos com base nos valores tidos como plausíveis para uma economia emergente como, por exemplo, a economia brasileira. Tomando $k=0.1$ chegamos ao resultado apresentado na Figura 4 abaixo:

FIGURA 4 - CURVAS COM OS PARÂMETROS UTILIZADOS E $k=0.1$

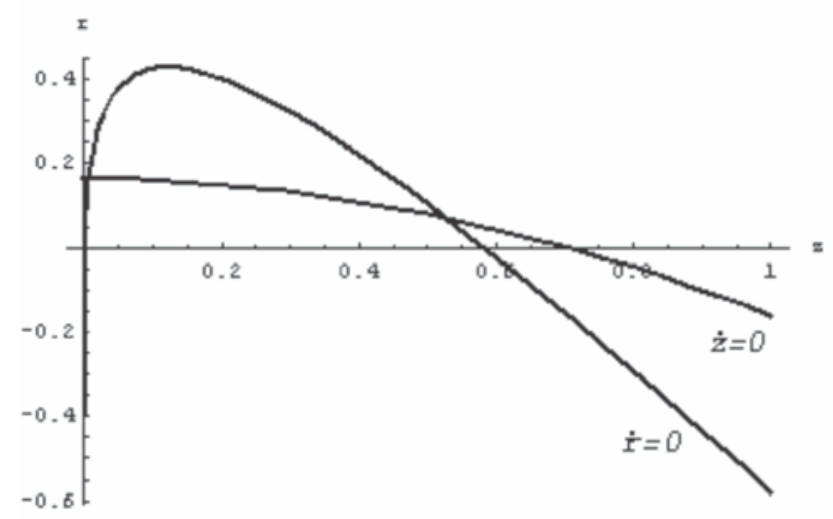

$\mathrm{Na}$ Figura 4 observamos a existência de dois equilíbrios. No primeiro, com baixo endividamento, a relação dívida/produto real é igual $0,75 \%$ e a lucratividade de $16,65 \%$. No segundo, com alto endividamento externo, a relação dívida/produto real é de $52,75 \%$ e lucratividade de $7,03 \%$.

\subsection{Dinâmica Comparada para o Caso de $\gamma<\infty$ Sob Diferentes Regimes de Conversibilidade}

$\mathrm{Na}$ análise de dinâmica comparada iremos utilizar os valores dos parâmetros definidos anteriormente (exceto o valor do índice de controle de capital, $k$ ), e analisaremos a trajetória das variáveis endógenas sob dois cenários diferentes para o valor inicial da dívida externa como proporção do nível de produto real, a saber: $10 \%$ e $25 \%$ do produto real (correspondentes a $z=0.1$ e $z=0.25$ ). Em cada um desses cenários iremos analisar o impacto de diferentes regimes de conversibilidade da conta de capitais (plena: $k=0$, ou parcial, $k=0.1$ ) sobre a dinâmica das variáveis econômicas. Vale ressaltar que o ponto inicial corresponde a uma situação de equilíbrio no mercado de bens, mas não necessariamente na dívida. 


\section{Cenário 1: Endividamento Inicial Baixo}

Na Figura 5 observamos que nos estágios iniciais da trajetória temporal da taxa de juros a plena-conversibilidade da conta de capitais gera uma taxa de juros mais alta do que a gerada por uma situação de controle (parcial) de capitais. Isto porque os controles de capitais permitem que o Banco Central fixe uma taxa de juros mais baixa do que a que prevaleceria numa situação de plena conversibilidade. De fato, em $t=0$ a taxa de juros doméstica num regime de plena-conversibilidade da conta de capitais seria de $6,98 \%$ por período, ao passo que num regime de conversibilidade parcial a mesma seria de $6,59 \%$ por período, dados os parâmetros usados na simulação. Isto ocorre porque o controle de capitais altera a taxa de juros inicial diretamente, como pode ser visto em $(8)$.

\section{FIGURA 5 - TAXA DE JUROS}

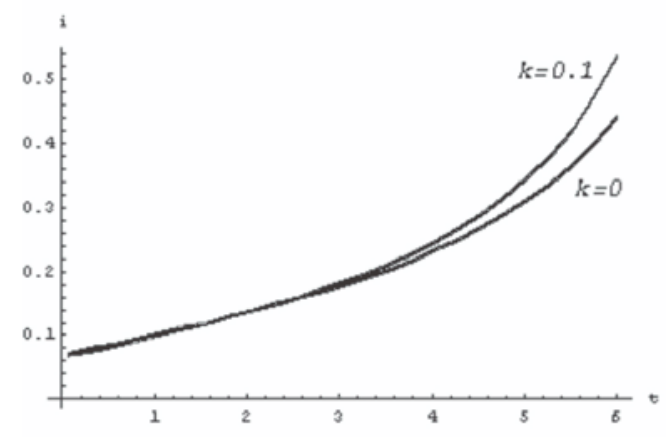

Com o tempo, contudo, essa relação é revertida: a taxa de juros doméstica num regime de plena-conversibilidade fica menor do que a prevalecente num regime de conversibilidade parcial da conta de capitais. Esse comportamento decorre da dinâmica do grau de utilização da capacidade produtiva e do endividamento externo: como a taxa de juros doméstica é mais baixa nos estágios iniciais da dinâmica temporal no caso de conversibilidade parcial do que no caso de conversibilidade plena, segue-se que o investimento e o grau de utilização da capacidade produtiva serão mais altos no primeiro caso do que no segundo. Um maior nível de utilização da capacidade produtiva irá gerar um valor menor para as exportações líquidas como proporção do produto real e, portanto, um acúmulo mais rápido de endividamento externo. Esta explicação é comprovada pela análise das Figuras 6, 7 e 8: 
FIGURA 6 - EXPORTAÇÕES LÍQUIDAS E/X)

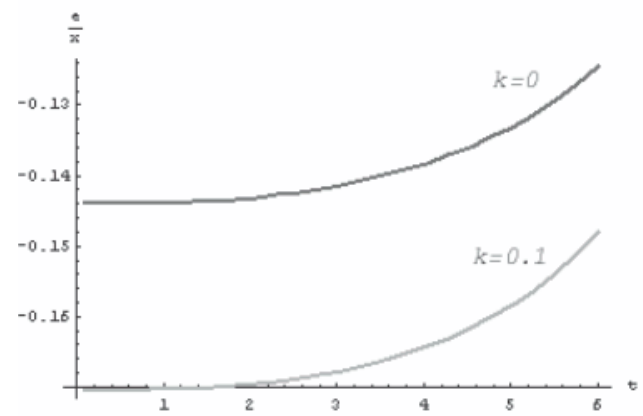

FIGURA 7 - DÍVIDA EXTERNA

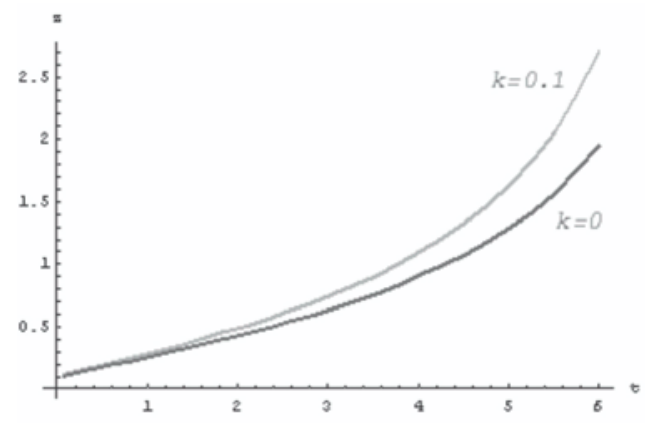

FIGURA 8 - TAXA DE LUCRO

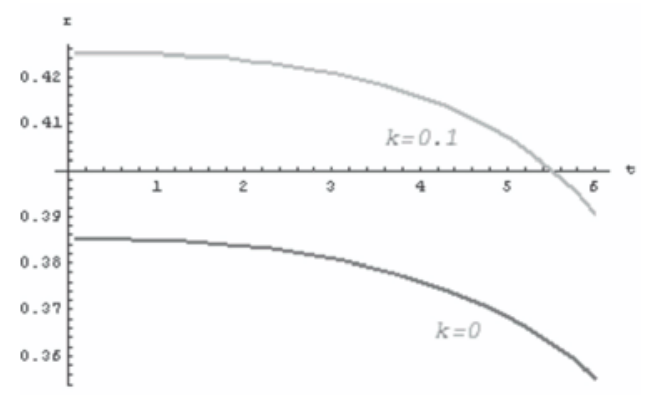

Cenário 2: Endividamento Inicial Alto

A dinâmica da taxa de juros sob diferentes regimes de conversibilidade da conta de capitais, no caso em que o nível inicial de endividamento externo é de $25 \%$ do produto real, é mostrado pela Figura 9: 


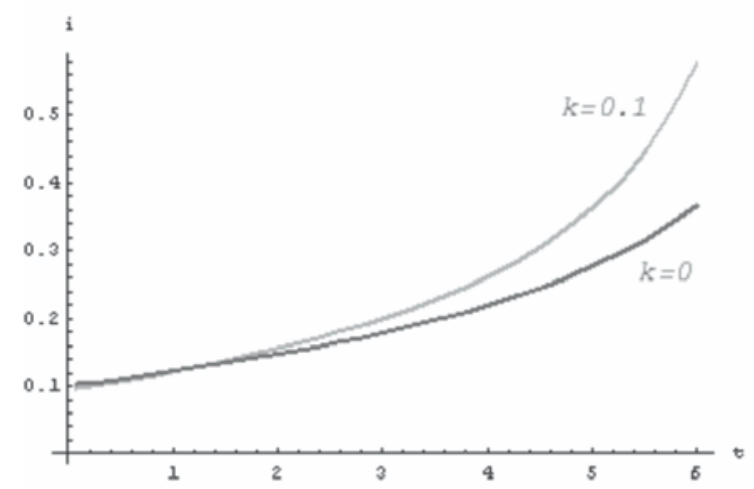

Tal como no caso anterior, observamos aqui que nos estágios iniciais da dinâmica temporal a taxa de juros é menor num regime de conversibilidade parcial do que num regime de plena-conversibilidade da conta de capitais. A diferença em relação ao caso anterior reside no patamar inicial da taxa de juros em ambos os regimes. Num regime de plena-conversibilidade, o valor inicial da taxa de juros doméstica é igual a $10 \%$ por período. Já num regime de conversibilidade parcial esse valor é igual a apenas $9,3 \%$ por período.

Na Figura 10 observamos a dinâmica temporal das exportações líquidas sob diferentes regimes de conversibilidade. Vemos aqui que as exportações líquidas como proporção do produto real mantêm-se menos deficitárias nos dois regimes, em comparação com o caso de endividamento inicial baixo. A razão para esse aparentemente "bom comportamento" do saldo comercial se deve ao efeito da taxa de juros mais alta sobre o grau de utilização da capacidade. Como o risco-país é mais alto no caso em que $z(0)=$ 0.25 do que no caso em que $z(0)=0.1$, segue-se que a taxa de juros será mais alta no primeiro caso do que no segundo. Dessa forma, o investimento e, conseqüentemente, o grau de utilização da capacidade produtiva será mais baixo no cenário 2 do que no cenário 1. Como as exportações líquidas são inversamente relacionadas com o grau de utilização, segue-se que o saldo da balança comercial será mais alto no cenário com endividamento médio do que no cenário com baixo endividamento. 
FIGURA 10 - EXPORTAÇÕES LÍQUIDAS (E/X)

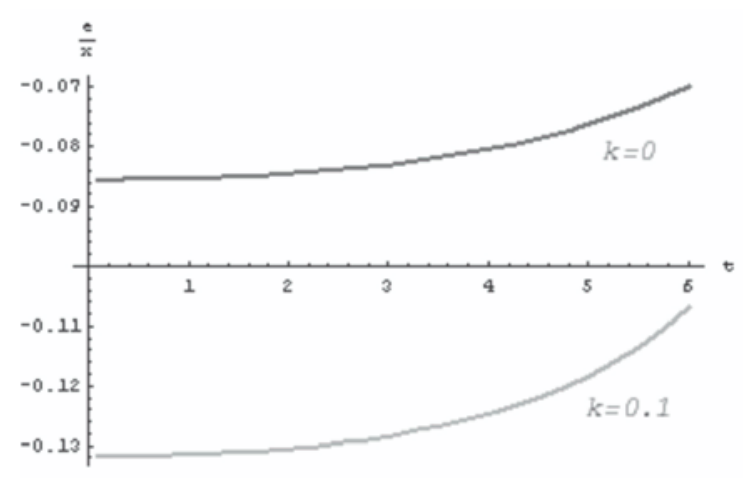

FIGURA 11 - DÍVIDA EXTERNA

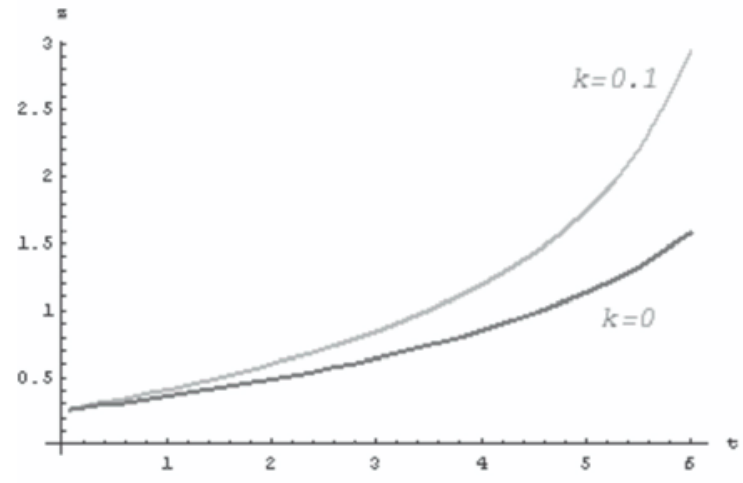

FIGURA 12 - TAXA DE LUCRO

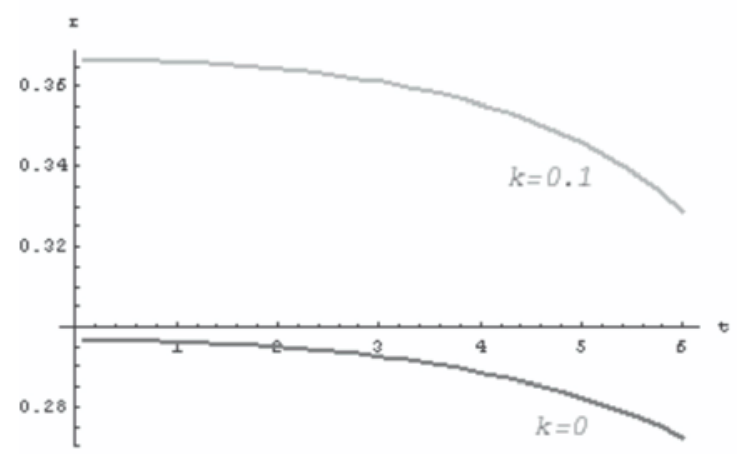




\subsection{Estática Comparativa para o Caso de $\gamma->\infty$ para Diferentes Cenários Conjunturais}

Como visto na seção 1.4, relaxando a suposição de ajuste lento no mercado de bens, temos a ocorrência de estabilidade no equilíbrio com alto endividamento. De fato, ao rodar a simulação dinâmica com os mesmos parâmetros iniciais da análise da seção 2.3 e incorporando o ajuste instantâneo no mercado de bens, verificamos uma convergência com baixa oscilação:

FIGURA 13 - LUCRATIVIDADE NO TEMPO

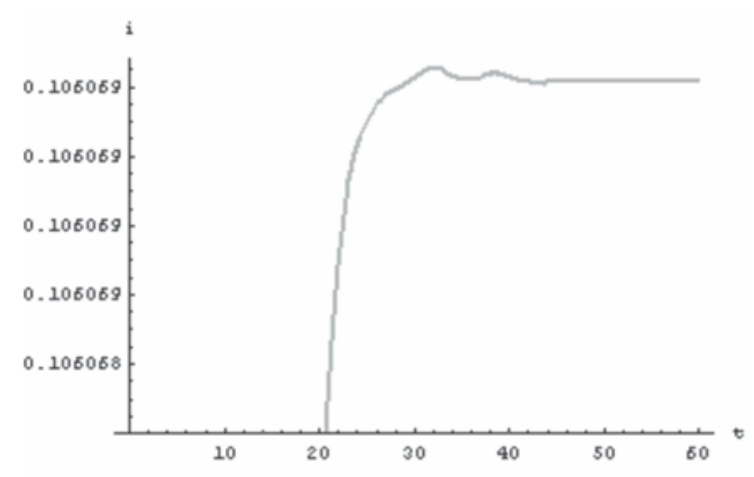

O gráfico mostra apenas o comportamento a partir de $\mathrm{t}=20$ para evidenciar as pequenas oscilaçóes convergentes que ocorrem devido ao ajuste causado pela dinâmica do endividamento externo (equação (19)). Podemos, desta forma, analisar as diferentes posições de equilíbrio a que a economia é levada em diferentes situações conjunturais e estruturais.

As Tabelas 2 e 3, adiante, mostram os resultados das simulações. Cada tabela analisa os impactos de variaçóes em uma determinada variável. A Tabela 2, por exemplo, mostra os valores de equilíbrio em três cenários: o cenário padrão utilizado no trabalho $\left(i^{*}=0.02\right)$, um aumento de 0,5 ponto porcentual $\left(i^{*}=0.025\right)$ e uma queda de 0,5 ponto porcentual $\left(i^{*}=0.015\right)$. Em cada um dos três casos, a tabela informa os valores de equilíbrio de $r$ e $z$ nos casos em que há liberalização na conta de capitais $(k=0)$ e em que há um controle de capitais $(k=0.1)$. Por exemplo, quando $i^{*}=0.015$, e há controle de capitais, os valores de equilíbrio da lucratividade e do endividamento são $5,87 \%$ e $57,24 \%$, respectivamente.

As tabelas mostram também as variações porcentuais nas variáveis endógenas em relação ao caso básico (destacado nas tabelas com sombreado) nos campos " $\Delta r_{1} / r$ e $\Delta z_{1} / z$ ” e " $\Delta r_{2} / r$ e $\Delta z_{2} / z$ ". As variaçôes com subscrito 1 (por exemplo $\Delta r_{1} / r$ ) referem-se ao 
primeiro caso de variação (ou seja, o valor logo à direita do caso básico), e as com subscrito 2 (por exemplo $\Delta z_{2} / z$ ) referem-se ao segundo caso de variação. Por exemplo, podemos ver na Tabela 2 - Variações na Taxa de Juros Internacional - que quando o valor autônomo das exportações líquidas passa de $\varepsilon_{0}=0.11$ para $\varepsilon_{0}=0.1$ na ausência de controle de capitais, a taxa de lucro de equilíbrio aumenta em 19,15\%, e a dívida de equilíbrio tem uma queda de $-38,37 \%$.

\section{Cenário 1 - Variações na Taxa de Juros Internacional}

Analisamos o impacto de uma variação (para cima ou para baixo) da taxa básica de juros internacional em $0,5 \%$. Os resultados são apresentados na Tabela 2.

Verificamos aqui um resultado inicialmente contra-intuitivo: quando há um aumento na taxa de juros internacional, a lucratividade de equilíbrio aumenta e o endividamento diminui. É importante ressaltar que estamos analisando posições de equilíbrio, e não impactos instantâneos. Em um primeiro momento, há uma redução da lucratividade (que possui ajuste instantâneo). Como a lucratividade está menor do que a que leva ao equilíbrio da dívida, a economia entra em uma trajetória de redução da dívida e aumento da lucratividade, que resulta em uma dívida menor e uma lucratividade maior que a inicial.

\section{Cenário 2 - Variações no Comércio Mundial}

A variável do modelo que reflete alterações no comércio internacional é $\varepsilon_{0}$, o componente autônomo das exportações líquidas, dado que o termo $\varepsilon_{1} u$ reflete as importações, que são induzidas pelas variações no grau de utilização da capacidade produtiva.

A primeira observação que se pode fazer dos resultados (veja Tabela 3 - Variações no Comércio Mundial) é o enorme impacto das alterações das exportações nos valores de equilíbrio. Isto ocorre porque a lucratividade que equilibra o mercado de bens é mais sensível às exportações líquidas do que a que equilibra a dívida. ${ }^{17}$ Este comportamento pode ser visualizado no gráfico comparativo das duas situações (Figura 14).

17 Uma alteração de $\Delta \varepsilon_{0}$ em $\varepsilon_{0}$ altera $r$ de equilíbrio em $\frac{\Delta \varepsilon_{0}}{\varepsilon_{1} m^{-1}-\alpha_{1}}$ em $\dot{r}=0$, e $\frac{\Delta \varepsilon_{0}}{\varepsilon_{1} m^{-1}}$ em $\dot{z}=0$. Como $\varepsilon_{1} m^{-1}-\alpha_{1}>0$ e $\alpha_{1}>0$, temos que $\frac{\Delta \varepsilon_{0}}{\varepsilon_{1} m^{-1}-\alpha_{1}}<\frac{\Delta \varepsilon_{0}}{\varepsilon_{1} m^{-1}}$, resultando, dessa forma, em $\Delta r_{\mid r=0}>\Delta r_{\mid z=0}$. 


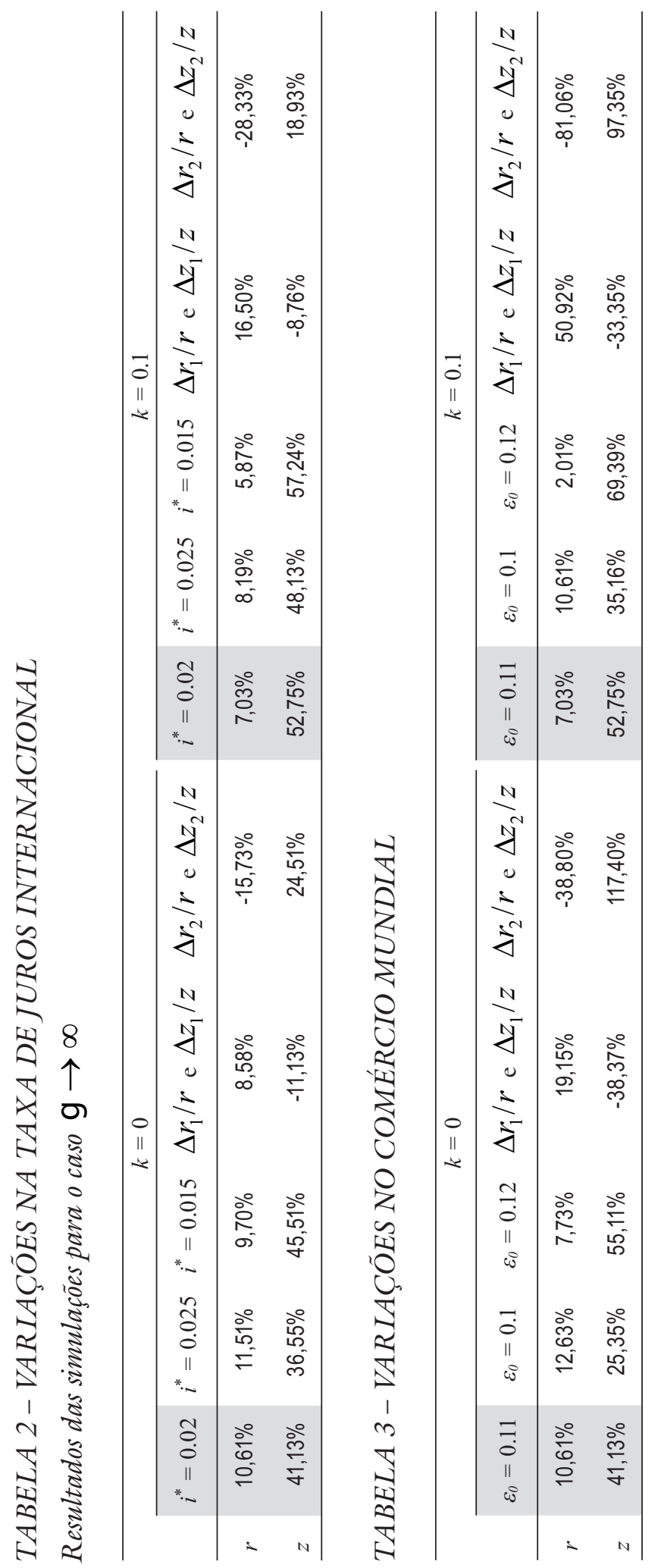

Estud. econ., São Paulo, 36(4): 747-777, out-dez 2006 


\section{FIGURA 14 - EFEITOS DE REDUÇÃO NO COMPONENTE AUTÔNOMO DAS EXPORTAÇÕES LÍQUIDAS}

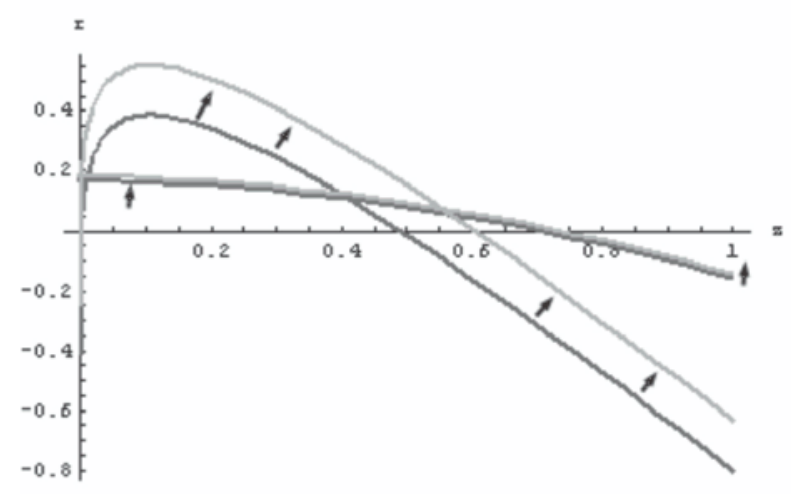

Em um contexto de depressão no mercado internacional, a presença de controle de capitais melhora a resposta do nível de atividade da economia à nova situação no equilíbrio. Por outro lado, a redução do endividamento de equilíbrio é menor. No caso de um aumento das exportações, no entanto, observamos o oposto. Na seção 2.5 analisamos esses diferentes comportamentos sob a perspectiva do bem-estar social.

\subsection{Análise de Bem-Estar}

Os resultados obtidos nas simulações da seção 2.4 permitiram a observação de relações de causa e conseqüência importantes para análises qualitativas e considerações conjunturais. As variaçóes verificadas ao se compararem os resultados na presença e na ausência de controle de capitais foi, no entanto, não-conclusiva. Em casos como a variação da taxa de juros internacional, o controle de capitais intensificou a variação na taxa de utilização da capacidade, mas atenuou, por outro lado, a variação no endividamento externo.

A análise de bem-estar para o controle de capitais exige, portanto, um método de quantificação de bem-estar. Para isso, inicialmente iremos supor que a sociedade almeja uma estabilidade nas variáveis endógenas do modelo (nível de atividade e endividamento externo). O peso que a sociedade dá para essas variações, no entanto, pode variar. Dois casos ilustram esse comportamento: a sociedade alemã, por exemplo, parece mostrar uma tolerância muito baixa a oscilações nos níveis de inflação, provavelmente devido a dois momentos traumáticos na sua história - as hiperinflações de 1923 e de 1948. A sociedade norte-americana, por outro lado, parece mostrar pouca 
tolerância com alta volatilidade nos níveis de emprego, devido à experiência da crise de 1929.

Dessa forma, analisaremos os diferentes níveis de bem-estar resultantes de diversos pesos que as sociedades podem dar à volatilidade de cada variável do modelo.

A volatilidade de $z$ em uma alteração de cenário econômico é a diferença entre o maior e o menor valor que ela adquire, e é dada pela equação (29). Da mesma forma, a volatilidade de $r$ em uma alteração de cenário econômico é dada pela equação (30):

$$
\begin{aligned}
& V_{z}=\left|\frac{\Delta z_{1}}{z}-\frac{\Delta z_{2}}{z}\right| \\
& V_{r}=\left|\frac{\Delta r_{1}}{r}-\frac{\Delta r_{2}}{r}\right|
\end{aligned}
$$

Iremos supor que a volatilidade é crescentemente custosa para a sociedade. Isto significa que uma alteração de $2 \%$ em uma variável tem um custo social maior do que o dobro do custo de uma alteração de $1 \%$. Chamaremos o peso que a sociedade dá para a volatilidade do nível de utilização da capacidade produtiva de $\Omega_{r}$ e para a volatilidade do endividamento externo de $\Omega_{z}$. Nossa função de custo social fica da seguinte forma:

$$
C S=\Omega_{r} V_{r}^{2}+\Omega_{z} V_{z}^{2}
$$

O bem-estar pode ser dado pelo negativo do custo social:

$$
B E=-C S
$$

Juntando (29) e (30) em (31) (lembrando que, ao elevar ao quadrado retira-se a necessidade de utilizar o módulo) e substituindo em (31) temos a equação de bem-estar que utilizaremos:

$$
B E=-\left(\Omega_{z}\left(\frac{\Delta z_{1}}{z}-\frac{\Delta z_{2}}{z}\right)^{2}+\Omega_{r}\left(\frac{\Delta r_{1}}{r}-\frac{\Delta r_{2}}{r}\right)^{2}\right)
$$

Analisamos agora dois casos de preferências das sociedades: aversão à volatilidade no endividamento externo e aversão à volatilidade no nível de atividade da capacidade produtiva. 


\begin{tabular}{lcc} 
TABELA & $4-$ AVERSÃO À VOLA- \\
& TILIDADE NO ENDIVI- \\
& DAMENTO EXTERNO \\
\hline & \multicolumn{2}{c}{ Bem-Estar } \\
\cline { 2 - 3 } & $K=0$ & $K=0.1$ \\
\hline Variações em $i$ & -0.11004 & -0.10775 \\
Variações em $\varepsilon_{0}$ & -1.90378 & -1.71665 \\
\hline
\end{tabular}

TABELA 5 - AVERSÃO À VOLATILIDADE NO NÍVEL DE ATIVIDADE DA CAPACIDADE PRODUTIVA

\begin{tabular}{lcc}
\hline & \multicolumn{2}{c}{ Bem-Estar } \\
\cline { 2 - 3 } & $K=0$ & $K=0.1$ \\
\hline Variações em $i^{*}$ & -0.07608 & -0.1699 \\
Variações em $\varepsilon_{0}$ & -0.85847 & -1.73347 \\
\hline
\end{tabular}

\section{Caso 1: Aversão à Volatilidade no Endividamento Externo}

Neste caso tomamos os seguintes valores para os parâmetros: $\Omega_{z}=0.75$ e $\Omega_{r}=0.25$.

Os resultados apresentados na Tabela 4 mostram que em uma sociedade com aversão à volatilidade no endividamento externo um maior controle de capitais aumenta $\mathrm{o}$ bem-estar em variações da taxa de juros internacional e do comércio exterior.

\section{Caso 2: Aversão à Volatilidade no Nivel de Atividade da Capacidade Produtiva}

Neste caso tomamos os seguintes valores para os parâmetros: $\Omega_{z}=0.25$ e $\Omega_{r}=0.75$. Os resultados podem ser vistos na Tabela 5 .

No caso de sociedade com aversão à volatilidade no nível de atividade da capacidade produtiva, a ausência de controle de capitais mostrou como resultado um maior bemestar para variações em todas as variáveis exógenas analisadas.

\section{CONCLUSÃO}

O presente trabalho teve por objetivo fazer uma análise teórica sobre o impacto dos controles de capitais em economias emergentes. A metodologia utilizada para alcançar esse objetivo foi a de análise de resultados de simulações em computador de um modelo teórico.

Os resultados mostraram que o papel do controle de capitais em uma economia pode ser muito mais complexo do que a simples análise de efeitos instantâneos e de curto prazo pode mostrar.

Nas seções 2.3 e 2.4, por exemplo, vimos que nos estágios iniciais da dinâmica o controle de capitais pode aumentar o nível de utilização da capacidade produtiva. 
Ao longo do tempo, no entanto, esse aumento no nível de utilização da capacidade leva a uma deterioração das contas externas, que leva, por sua vez, a um aumento do endividamento externo e à conseqüente redução do nível de utilização da capacidade produtiva.

Como os resultados referentes às alterações na volatilidade das variáveis macroeconômicas não são imediatamente conclusivos, foi feita uma análise de bem-estar da sociedade, que mostrou que a opção pela adoção ou não do controle de capitais depende do nível de aversão da sociedade à volatilidade das diferentes variáveis macroeconômicas. Neste contexto, se a sociedade tiver uma forte aversão à volatilidade da dívida externa - como parece ser o caso da maior parte dos países latino-americanos -, então os controles de capitais serão preferíveis a uma situação de plena conversibilidade da conta de capitais. Contudo, se a sociedade tiver uma forte aversão à volatilidade do grau de utilização da capacidade, dando pouca importância à volatilidade da dívida externa - como parece ser o caso dos países desenvolvidos -, então a plena conversibilidade da conta de capitais será a escolha que maximiza o bem-estar da sociedade.

Sendo assim, a escolha do regime de conversibilidade da conta de capitais não pode ser baseada unicamente em critérios técnico-econômicos, porquanto depende das preferências dos indivíduos que compóem essa sociedade.

\section{REFERÊNCIAS BIBLIOGRÁFICAS}

Bresser, L. C; Nakano, Y. Crescimento econômico com poupança externa? Revista de Economia Política, v. 23, n. 2, 2003.

Blanchard, S; Fisher, F. Lectures on macroeconomics. Cambridge: MIT Press, 1989.

Blatt, J. M. Dynamic economic systems: a post Keynesian approach. Nova Iorque: M. E. Sharpe, 1983.

Carvalho, F. C.; Sicsú, J. Controvérsias recentes sobre controle de capitais. Revista de Economia Politica, v. 24, n. 2, p. 163-184, 2004.

Fleming, M. Domestic financial policies under fixed and under floating exchange rates. IMF Staff Papers, 9, 1962.

Kaldor, N. Alternative theories of distribution. Review of Economic Studies, XXIII, p. 83-100, 1956.

The irrelevance of equilibrium economics. Economic Journal, 82, p. 123755,1972 .

Mundell, R. A. International economics. Nova Iorque: Macmillan Publishing Co., 1968. 
Oreiro, J. L. Poupança externa e performance macroeconômica: uma análise a partir de um modelo dinâmico não-linear de acumulação de capital e endividamento externo. Revista de Economia Politica, v. 24, n. 2, p. 185-200, 2004.

Pasinetti, L. Rate of profit and income distribution in relation to the rate of economic growth. Review of Economic Studies, v. XXIX, n. 4, p. 267-79, 1962.

Paula, L. F.; Oreiro, J. L.; Jonas, G. Fluxos e controles de capitais no Brasil: avaliação e proposta de política. In: Sicsú, J.; Oreiro, J. L; Paula, L. F., Agenda Brasil: políticas econômicas para o crescimento com estabilidade de preços. São Paulo: Manole, 2003.

Rodrik, D. Who needs capital-account convertibility? Essays in International Finance, Princeton, n. 207, p. 55-65, 1998.

Samuelson, P. Fundamentos da análise econômica. São Paulo: Abril Cultural, 1983 [Edição Original: 1945].

Simon, H. A racionalidade do processo decisório em empresas. Edições Multiplic, v. 1, n. 1, 1980.

Simonsen, M. H; Cysne, R. P. Macroeconomia. São Paulo: Atlas, 1995.

Stiglitz, J. Bleak growth prospects for the developing world. International Harold Tribune, 10 de abril de 1999, p. 6.

Capital market liberalization, economic growth and instability. World Development, v. 28, n. 6, p. 1075-1086, 2000.

Takayama, A. Analytical methods in economics. Michigan: The University of Michigan Press, 1993.

Taylor, L. Macroeconomia estruturalista. Cidade do México: Trillas, 1989.

Tobin, J. A proposal for international monetary reform. Eastern Economic Journal, v. $4,1978$. 